\title{
PENGARUH PENGGUNAAN MODEL PROJECT BASED LEARNING DAN KETERAMPILAN KOLABORASI TERHADAP HASIL BELAJAR SISWA KELAS IV SEKOLAH DASAR PADA TEMA CITA-CITAKU
}

\author{
Lindra Nur Khanifah ${ }^{1}$, Mustaji $^{2}$, Nasution ${ }^{3}$ \\ ${ }^{1}$ Mahasiswa Program Pascasarjana, Prodi Pendidikan Dasar, Universitas Negeri Surabaya, \\ ${ }^{2 \& 3}$ Dosen Pascasarjana, Prodi Pendidikan Dasar, Universitas Negeri Surabaya \\ e-mail: lindra.10209@gmail.com
}

Received : November 2018

Reviewed : Desember 2018

Accepted : Januari 2019

Published : Januari 2019

\section{ABSTRACT}

This study have purpose research the effect of using Project Based Learning model toward the learning output student of grade IV elementary school and the effect of using collaboration skill toward the learning output student of grade IV elementary school. The type of the research was experimental research with pretest-posttest control group research design.. Results of testing the hypothesis that $t$ value obtained is equal to 7.259 and a significance value of 0.002, the hypothesis testing results show that the $t$ value obtained is greater than the value of $t$ in the table 7.259 $>2.920)$, while the significance value smaller than the value of $\alpha(0.002<0.05)$. Based on these results, the hypothesis is accepted, it be concluded that project based learning models and collaboration skill can improve the learning outputs of the student grade IV SDN Kutorejo 1 Tuban significantly.

Keywords: Project Based Learning, Collaboration Skill, Learning Output.

\section{ABSTRAK}

Penelitian ini bertujuan untuk menganalisa pengaruh model Project Based Learning terhadap hasil belajar dan keterampilan kolaborasi terhadap hasil belajar siswa kelas IV SD. Jenis penelitian yang dilakukan adalah penelitian eksperimen dengan bentuk penelitian pretest-posttest control group design.. Hasil pengujian hipotesis menjelaskan nilai f hitung yang didapat yaitu sebesar 7.259 dan nilai signifikansi sebesar 0,002, hasil pengujian hipotesis tersebut menunjukkan bahwa nilai f hitung yang didapat lebih besar dari nilai $t$ dalam tabel $(7.259>2.920)$ sedangkan nilai signifikansi tersebut lebih kecil dari nilai $\alpha(0,002<0,05)$. Berdasar hasil tersebut, maka hipotesis diterima, artinya terdapat pengaruh yang signifikan antara model project based learning dan keterampilan kolaborasi terhadap hasil belajar siswa kelas IV SD Negeri Kutorejo 1 Tuban.

Kata Kunci : Project Based Learning, Keterampilan Kolaborasi, Hasil Belajar.

\section{PENDAHULUAN}

Seiring dengan perkembangan global, ilmu pengetahuan berkembang semakin cepat sehingga tidak mungkin lagi para guru mengajarkan semua fakta dan konsep kepada siswa. Dalam cakupan Standar Kompetensi Lulusan (SKL) satuan pendidikan yaitu pada domain keterampilan, anak diharapkan memiliki pribadi yang berkemampuan pikir dan tindak yang efektif dan kreatif dalam ranah abstrak dan konkret (Kemendikbud, 2014). Keterampilan berpikir sangat penting bagi siswa, khususnya berpikir kritis, karena pengaruh globalisasi dan perkembangan ilmu pengetahuan serta teknologi yang semakin cepat. Mengharuskan siswa untuk merespon perubahan dengan cepat dan efektif sehingga memerlukan keterampilan intelektual yang fleksibel, kemampuan menganalisis informasi dan mengintegrasikan berbagai sumber pengetahuan untuk menyelesaikan permasalahan, juga berguna untuk memilih yang terbaik diantara pilihan yang ada. Vernon (1998:178) menyatakan bahwa "students learn best and behave more appropiattely in classroom 
settings that meet their learning needs." Siswa dapat belajar dengan baik, berperilaku lebih baik di dalam kelas agar dapat memenuhi kebutuhan belajar mereka. Banyak penyebab yang melatar belakangi mengapa pembelajaran dengan menggunakan tema belum dapat memberikan hasil seperti yang diharapkan. Faktor penyebabnya dapat berpangkal pada kurikulum, rancangan, pelaksana, pelaksanaan, model pembelajaran, ataupun faktor-faktor pendukung pembelajaran yang lainnya. Dalam proses pembelajaran yang menyangkut materi, metode, media alat peraga dan sebagainya harus juga mengalami perubahan ke arah pembaharuan (inovasi). Dengan adanya inovasi tersebut, seorang guru dituntut untuk lebih kreatif dan inovatif terutama dalam menentukan model dan metode yang tepat, karena hal ini sangat menentukan keberhasilan siswa terutama pembentukan kecakapan hidup (life skill) siswa yang berpijak pada lingkungan sekitarnya. Berdasarkan hasil observasi awal yang peneliti lakukan di SDN Kutorejo 1 Tuban, diperoleh informasi bahwa dalam pembelajaran yang berpacu pada kurikulum 2013 di kelas IV pada beberapa hal sudah memperoleh keberhasilan. Diantaranya adalah walaupun guru menggunakan metode ceramah, siswa terlihat memperhatikan guru ketika proses pembelajaran dari awal guru melakukan apersepsi hingga guru melakukan evaluasi di akhir pembelajaran. Namun ada beberapa masalah yang peneliti temukan ketika proses pembelajaran berlangsung. Diantaranya adalah (1) guru masih cenderung mendominasi kegiatan pembelajaran, (2) guru hanya sebatas menggunakan papan tulis tidak menggunakan media pembelajaran lainnya yang relevan untuk menunjang kegiatan pembelajaran, (3) guru belum memberikan reward kepada siswa yang aktif berpartisipasi dalam kegiatan pembelajaran, (4) dalam pembelajaran, guru belum mengembangkan berbagai keterampilan siswa yang berhubungan dengan interaksi sosial sesama teman atau disebut keterampilan sosial, (5) selain menerapkan metode ceramah, guru juga menerapkan kegiatan pembelajaran berkelompok namun tidak sepenuhnya berhasil.

Masalah-masalah tersebut berdampak pada aktivitas siswa di dalam kelas, diantaranya adalah: (1) banyak siswa yang kurang tergerak aktif untuk mencari informasi sendiri dari sumber lain, (2) siswa cenderung hanya duduk, mendengarkan, dan mencatat apa yang disampaikan oleh guru, (3) siswa yang aktif mengemukakan pendapat terbatas pada beberapa anak saja, (4) siswa kurang menghargai ketika ada teman yang mengemukakan pendapat yang berbeda, (5) dalam kelompok, banyak ditemukan siswa yang hanya menggantungkan diri kepada siswa lainnya saat mengerjakan tugas yang diberikan oleh guru, (6) terbentuknya beberapa kelompok bermain (grup) dalam satu kelas, ada kelompok bermain (grup) yang diam dan ada kelompok bermain (grup) yang vokal (banyak bicara).

Permasalahan-permasalahan di atas, diduga karena guru masih memiliki pemikiran bahwa sumber pembelajaran hanya terpusat pada dirinya. Selain itu guru juga belum terbiasa menerapkan model pembelajaran inovatif yang dapat mengembangkan keterampilan berkolaborasi siswa selama kegiatan pembelajaran berkelompok. Hal ini terlihat ketika dalam proses pembelajaran guru kurang memberikan bimbingan kepada siswanya.

Dari permasalahan-permasalahan di atas, salah satu masalah yang harus segera diatasi adalah tentang kemampuan siswa dalam hal keterampilan yang harus dimiliki dalam pembelajaran kurikulum 2013. Keterampilan sosial ini relevan untuk dikembangkan dalam pengimplementasian pembelajaran kurikulum 2013 agar kelak para siswa dapat hidup sebagai warga masyarakat, warga negara, serta warga dunia yang dapat berperan dalam lingkupnya.

Salah satu strategi pembelajaran yang dapat membantu peserta didik agar memiliki kreativitas berpikir,pemecahan masalah, dan interaksi serta membantu dalam penyelidikan yang mengarah pada penyelesaian masalah nyata adalah project based learning atau pembelajaran berbasis proyek Buck Institute for Education (BIE) (dalam Khamdi, 2007). Dengan pembelajaran berbasis proyek, maka pembelajaran IPS tidak semata - mata menghafal konsep, dan pengetahuan yang bersifat kognitif rendah lainnya serta guru sebagai satu-satunya sumber informasi melainkan akan membawa peserta didik untuk berpartisipasi aktif, karena mereka akan diminta melakukan berbagai tugas, seperti bekerja kelompok, berinteraksi dengan teman, mengajukan pendapat selama pembelajaran. Ini berarti bahwa guru bukan satu - satunya yang memberikan informasi karena peserta didik akan mencari sumber yang beragam dan terlibat dalam berbagai kegiatan yang beragam pula. Model pemberian proyek termasuk salah satu jenis belajar aktif. Menurut Dewey (dalam Moeslichatoen, 2004:137) dikatakan sebagai model pembelajaran learning by doing. Hal ini berarti bahwa proses belajar diperoleh melalui aktivitas atau kegiatan yang dilakukan anak sendiri atau berkelompok, dengan pengertian yaitu bagaimana anak melakukan pekerjaan sesuai dengan langkah dan rangkaian tingkah laku tertentu. Dengan adanya proses melakukan diharapkan proses tersebut mampu member pengalaman yang berpengetahuan anak, sehingga anak mampu 
memahami dan mengerti secara lebih dalam karena hal tersebut.

Model pembelajaran yang efektif, efisien, serta menyenangkan diharapkan dapat memotivasi siswa dalam belajar sehingga aktivitas siswa dalam belajar terus meningkat. Model pembelajaran yang efektif, efisien, dan menyenangkan yang akan peneliti terapkan adalah model Project Based Learning (PjBL). Keunggulan model pembelajaran berbasis proyek ini adalah mengembangkan keterlibatan total setiap individu dalam proses kegiatan pembelajaran. Model pembelajaran ini merupakan model pembelajaran yang berorientasi aktivitas siswa dan juga cocok untuk memastikan akuntabilitas individu dalam diskusi/kinerja kelompok.

Pada penelitian ini rumusan masalahnya antara lain (1) Apakah penggunaan model pembelajaran berbasis proyek berpengaruh terhadap hasil belajar siswa kelas IV sekolah dasar pada tema cita-citaku?(2) Apakah keterampilan berkolaborasi berpengaruh terhadap hasil belajar siswa kelas IV sekolah dasar pada tema cita-citaku? (3) Apakah ada hubungan antara penggunaan model pembelajaran berbasis proyek dan keterampilan berkolaborasi siswa kelas IV sekolah dasar pada tema citacitaku?.

Terdapat beberapa manfaat penelitian yang dapat diperoleh siswa, guru, sekolah maupun peneliti. Rinciannya adalah Bagi guru:guru akan memperoleh alternatif baru dalam menggunakan model pembelajaran. Sedangkan bagi siswa : termotivasi dalam pembelajaran kelompok sehingga dapat meningkatkan hasil belajar mereka. Bagi sekolah: memperbaiki kualitas lulusan dari sekolah, karena adanya peningkatan cara mengajar guru dalam proses pembelajaran dan bagi peneliti sendiri memberikan pengalaman yang berharga bagi peneliti sebagai calon tenaga pendidik untuk menigkatkan aktivitas belajar siswa dalam mengikuti pembelajaran kurikulum 2013 sehingga prestasi belajar yang diharapkan dapat tercapai dengan maksimal.

Model pembelajaran adalah suatu perencanaan atau suatu pola yang digunakan sebagai pedoman dalam merencanakan pembelajaran di kelas atau pembelajaran dalam tutorial (Trianto,2011: 51). Dengan menggunakan model dimaksudkan menjadi sebuah ciri utama dalam proses pembelajaran sebagai langkah awal untuk melaksanakan pembelajaran di kelas. Menurut Usman (2010:21) mengajar adalah membimbing kegiatan belajar siswa sehingga ia mau belajar. Sementara itu pembelajaran adalah suatu usaha yang sengaja melibatkan dan menggunakan pengetahuan professional yang dimiliki guru untuk mencapai tujuan kurikulum. Pembelajaran secara umum adalah kegiatan yang dilakukan guru sehingga tingkah laku siswa berubah kearah yang lebih baik (Hamdani, 2011:71).

Project Based Learning merupakan model pembelajaran yang mana menekankan pada penggunaan sebuah kegiatan atau proyek sebagai media pendukung pembelajaran. Para siswa diharapkan untuk bisa melakukan eksplorasi, penilaian, interpretasi, sintesis, dan informasi untuk menghasilkan berbagai bentuk hasil belajar. Project Based Learning memiliki karakteristik (Kemendikbud, 2013: 210) sebagai berikut : (a) peserta didik membuat keputusan tentang sebuah kerangka kerja, (b) adanya permasalahan atau tantangan yang diajukan kepada peserta didik (c) peserta didik mendesain proses untuk menentukan solusi atas permasalahan atau tantangan yang diajukan, (d) peserta didik secara kolaboratif bertanggung jawab untuk mengakses dan mengelola informasi untuk memecahkan permasalahan, (e) proses evaluasi dijalankan secara kontinyu, (f) peserta didik secara berkala melakukan refleksi atas aktivitas yang sudah dijalankan, (g) produk akhir aktivitas belajar akan dievaluasi secara kuanntitatif; dan (h)situasi pembelajaran sangat toleran terhadap kesalahan dan perubahan.

Pada modul pelatihan kurikulum (2013:11) dijelaskan bahwa keuntungan pembelajaran berbasis proyek antara lain : (a)meningkatkan motivatisi belajar siswa untuk belajar, mendorong kemampuan mereka untuk melakukan pekerjaan penting dan mereka perlu untuk dihargai, (b) meningkatkan kemampuan pemecahan masalah, (c) membuat siswa menjadi lebih aktif dan berhasil memcahkan problem problem yang kompleks, (d) meningkatkan kolaborasi, (e) mendorong peserta didik untuk mengembangkan dan mempraktikkan keterampilan komunikasi, (f) meningkatkan keterampilan siswa dalam mengelola sumber, (g) memberikan pengalaman kepada siswa tentang pembelajaran dan praktik dalam mengorganisasi proyek, dan sumber sumber lain seperti perlengkapan untuk menyelesaikan tugas, (h) menyediakan pengalaman belajar yang melibatkan siswa secara kompleks dan dirancang untuk berkembang sesuai dunia nyata, (i) melibatkan para siswa untuk belajar mengambil informasi dan menunjukkan pengetahuan yang dimiliki, kemudian diimplementasikan dengan dunia nyata.

Langkah-langkah pelaksanakan pembelajaran Berbasis Proyek dapat dijelaskan dengan diagram sebagai berikut : 


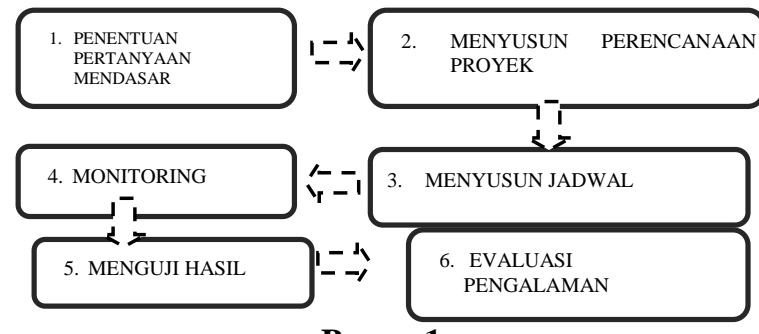

Bagan 1.

Langkah-Langkah Pelaksanakan Pembelajaran Berbasis Proyek

Collaborative learning ini sangat berakar dalam pandangan Vygotsky bahwa ada sebuah sifat sosial yang melekat pada pembelajaran, yang tercermin melalui teorinya tentang zona pengembangan proksimal. Sering kali, pembelajaran kolaboratif digunakan sebagai istilah umum untuk berbagai pendekatan dalam pendidikan itu. Melibatkan upaya intelektual bersama oleh siswa atau siswa dan guru. Kegiatan belajar secara kolaboratif dapat mencakup penulisan kolaboratif, proyek kelompok, pemecahan masalah secara bersama, debat, studi tim, dan kegiatan lainnya. Pendekatan ini terkait erat dengan pembelajaran kooperatif (Mustaji, 2010:24).

Howard (1999) menyarankan sebaiknya tim terdiri dari tiga sampai dengan lima orang agar dapat bekerja secara efektif. Ia juga menyarankan jumlah anggota sebaiknya gasal, jangan genap agar kalau suatu saat terjadi konflik dapat diatasi dengan voting dalam penyelesaiannya. Bowen (1998:274) mengingatkan bahwa keragaman latar belakang pebelajar juga perlu diperhatikan dan latar belakang mana yang akan lebih diberikan tekanan._Hal terpenting adalah apapun bentuk proses yang ditempuh dalam membangun tanggung jawab itu, para anggota tim harus memahami betul bahwa mereka bertanggungjawab terhadap semua pertemuan yang diselenggarakan oleh tim, memberikan sumbangan terhadap kegiatan diskusi dalam tim, dan menyelesaikan tugas-tugas tim secara baik dan tepat waktu (Utomo Dananjaya, 2012:142).

Hasil belajar merupakan bagian terpenting dalam pembelajaran. Nana Sudjana (2009: 3) mendefinisikan hasil belajar siswa pada hakikatnya adalah perubahan tingkah laku sebagai hasil belajar dalam pengertian yang lebih luas mencakup bidang kognitif, afektif, dan psikomotorik. Dimyati dan Mudjiono (2006: 3-4) juga menyebutkan hasil belajar merupakan hasil dari suatu interaksi tindak belajar dan tindak mengajar. Dari sisi guru, tindak mengajar diakhiri dengan proses evaluasi hasil belajar. Dari sisi siswa, hasil belajar merupakan berakhirnya pengajaran dari puncak proses belajar.

Faktor kemampuan siswa besar sekali pengaruhnya terhadap hasil belajar yang dicapai. Seperti dikemukakan oleh Clark bahwa hasil belajar siswa disekolah $70 \%$ dipengaruhi oleh kemampuan siswa dan $30 \%$ dipengaruhi oleh lingkungan (dalam Sudjana, 2004:39). Selain kedua faktor diatas, ada faktor lain yang turut menentukan hasil belajar siswa yaitu faktor pendekatan pembelajaran (approach to learning). Ini berkaitan dengan upaya belajar yang dilakukan siswa yang meliputi strategi dan metode pembelajaran (Robertus Angkowo dan A. Kosasih, 2007:51). Dengan memperhatikan berbagai penjelasan tentang hasil belajar maka penelitian ini akan mengukur keberhasilan belajar siswa pada tema kerukunan dengan materi pembuatan denah khususnya pada domain afektif dan psikomotor sebagai hasil belajar yang akan dikorelasikan dengan model pembelajaran kolaboratif dan ketrampilan siswa itu sendiri.

\section{METODE PENELITIAN}

Penelitian yang dilakukan peneliti merupakan penelitian eksperimen Dimana penelitian ini didasari oleh filsafat positivism logis (logical positivism) yang beroperasi dengan aturan aturan yang ketat mengenai logika, kebenaran, hukum hukum dan prediksi (Danum, 2002). Fokus penelitian kuantitatif ini diidentifikasikan sebagai proses kerja yang berlangsung secara ringkas, terbatas dan memilah permasalahan menjadi bagian yang dapat diukur dan dinyatakan dalam bentuk angka (nominal).

Penelitian ini terdiri atas empat kelompok dengan menggunakan desain pretest posttest control group desain Wiersma, 1991:108). Alasannya, desain ini merupakan desain yang sempurna, mempunyai kontrol yang ketat, sehingga memiliki tingkat validitas, kredibilitas dan objektivitas yang tinggi jika dibandingkan dengan desain eksperimen yang lain. Subjek penelitian adalah adalah siswa kelas IV paralel kelas A dan B SDN Kutorejo 1 Tuban tahun ajaran 2015/2016 yang berjumlah 30 siswa pada masing masing kelas. Dimana 30 siswa kelas IVA menjadi kelas eksperimen dan 30 siswa kelas IVB menjadi kelas kontrol.

Sesuai dengan jenis data yang diperoleh maka metode pengumpulan data dalam penelitian ini adalah sebagai berikut: (1) lembar keterlaksanaan model PjBL, (2) angket keterampilan kolaborasi siswa, dan (3) tes unjuk kerja. Sebelum tes objektif digunakan mengambil data, soal tes diuji cobakan kepada siswa di luar sampel. Setelah itu, dilakukan uji validitas dan uji reliabilitas.

Teknik pengumpulan data yang dilakukan dalam penelitian ini adalah pemberian tes. Pemberian tes dilakukan untuk mengetahui tingkat hasil belajar siswa terhadap materi pembelajaran. Penilaian dikenakan secara 
individu dan klasikal. Tes diberikan dalam dua tahap yaitu pada tahap pretest dan posttest.

Seluruh data yang telah diperoleh (terkumpul) akan dianalisa dengan teknik analisa data deskriptif dan inferensial. Menurut Arikunto (1989: 333), analisa data deskriptif bertujuan untuk menilai sejauh mana variabel yang diteliti telah sesuai dengan tolok ukur yang sudah ditentukan. Sedangkan analisa data inferensial merupakan cara ilmiah untuk membantu peneliti yang mempunyai subjek terbatas. Terdapat uji Normalitas, uji Homogenitas dan Uji Hipotesa.

Variabel dalam penelitian adalah segala sesuatu yang dijadikan obyek pengamatan dalam penelitian (Arikunto, 2010). Variabel yang diamati dalam penelitian ini adalah (1) model Project Based Learning, (2) keterampilan kolaborasi, (3) hasil belajar.

\section{HASIL DAN PEMBAHASAN}

A. Deskripsi Hasil Validasi

1. Hasil Validasi RPP Model Project Based Learning (PjBL)

Tabel 1.

Hasil Validasi Perangkat Pembelajaran Model PjBL

\begin{tabular}{|c|c|c|c|c|c|c|}
\hline \multirow[t]{3}{*}{ No } & \multicolumn{6}{|c|}{ Validitas } \\
\hline & \multicolumn{2}{|c|}{ Kelayakan Isi } & \multicolumn{2}{|c|}{ Penyajian } & \multicolumn{2}{|c|}{ Bahasa dan Keterbacaan } \\
\hline & Val.1 & Val.2 & Val.1 & Val.2 & Val.1 & Val.2 \\
\hline 1 & 4 & 3 & 4 & 3 & 4 & 3 \\
\hline$\overline{2}$ & 3 & 3 & 4 & 3 & 3 & 3 \\
\hline 3 & 4 & 3 & 4 & 3 & 4 & 3 \\
\hline 4 & 3 & 3 & 4 & 3 & 4 & 3 \\
\hline 5 & 4 & 3 & 3 & 3 & 3 & 3 \\
\hline 6 & 3 & 3 & 4 & 3 & 4 & 3 \\
\hline 7 & 4 & 3 & 4 & 3 & 3 & 3 \\
\hline 8 & 3 & 3 & 4 & 3 & 3 & 3 \\
\hline 9 & 4 & 3 & 4 & 3 & 4 & 3 \\
\hline 10 & 4 & 3 & 4 & 3 & 4 & 3 \\
\hline
\end{tabular}

Sumber : data yang sudah diolah

Hasil validasi Perangkat Pembelajaran dari kedua validator pada tabel 1 menunjukkan bahwa perangkat pembelajaran dinyatakan baik dan dapat digunakan.

\section{Hasil Validasi Angket Keterampilan Kolaborasi}

Tabel 2.

Hasil Validasi Keterampilan Berkolaborasi

\begin{tabular}{|c|c|c|c|c|c|c|c|c|}
\hline \multirow[t]{3}{*}{ No } & \multicolumn{8}{|c|}{ Validitas } \\
\hline & \multicolumn{2}{|c|}{ Kelayakan Isi } & \multicolumn{2}{|c|}{ Isi } & \multicolumn{2}{|c|}{$\begin{array}{l}\text { Bahasa dan } \\
\text { Keterba-caan }\end{array}$} & \multicolumn{2}{|c|}{ Keberman-faatan } \\
\hline & Val.1 & Val.2 & Val.1 & Val.2 & Val.1 & Val.2 & Val.1 & Val.2 \\
\hline 1 & 3 & 3 & 3 & 3 & 3 & 3 & 4 & 3 \\
\hline 2 & 4 & 3 & 3 & 3 & 4 & 3 & 4 & 3 \\
\hline 3 & 4 & 3 & 4 & 3 & 4 & 3 & 4 & 3 \\
\hline 4 & 4 & 3 & 4 & 3 & 4 & 3 & 4 & 3 \\
\hline 5 & 3 & 3 & 3 & 3 & 3 & 3 & 3 & 3 \\
\hline 6 & 3 & 3 & 3 & 3 & 3 & 3 & 4 & 3 \\
\hline 7 & 3 & 3 & 3 & 3 & 3 & 3 & 4 & 3 \\
\hline 8 & 3 & 3 & 4 & 3 & 3 & 3 & 3 & 3 \\
\hline 9 & 4 & 3 & 4 & 3 & 4 & 3 & 4 & 3 \\
\hline 10 & 3 & 3 & 4 & 3 & 4 & 3 & 4 & 3 \\
\hline
\end{tabular}

Hasil validasi angket keterampilan berkolaborasi dari kedua validator pada tabel 2 menunjukkan bahwa angket keterampilan berkolaborasi valid dapat dipahami daengan 10 butir pernyataan.

\section{Hasil Validasi Tes Hasil Belajar}

Tabel 3.

Hasil Validasi Tes Hasil Belajar

\begin{tabular}{ccccc}
\hline No & \multicolumn{2}{c}{ Validitas } & \multicolumn{2}{c}{ Konstruk } \\
\hline & \multicolumn{2}{c}{ Kelayakan Isi } & Val.1 & Val.2 \\
$\mathbf{1}$ & Val.1 & Val.2 & 4 & 3 \\
$\mathbf{2}$ & 3 & 3 & 4 & 3 \\
$\mathbf{3}$ & 4 & 3 & 4 & 3 \\
$\mathbf{4}$ & 3 & 3 & 4 & 3 \\
$\mathbf{5}$ & 4 & 3 & 3 & 3 \\
$\mathbf{6}$ & 4 & 3 & 4 & 3 \\
$\mathbf{7}$ & 4 & 3 & 4 & 3 \\
$\mathbf{8}$ & 3 & 3 & 3 & 3 \\
$\mathbf{9}$ & 4 & 3 & 3 & 3 \\
$\mathbf{1 0}$ & 4 & 3 & 4 & 3 \\
\hline \multicolumn{5}{r}{} \\
\end{tabular}

Hasil validasi tes hasil belajar dari kedua validator pada tabel 3 menunjukkan bahwa tes hasil belajar baik dan dapat dipahami dengan 10 butir soal.

\section{B. Deskripsi Hasil Uji coba}

\section{Tes Hasil Belajar}

\section{a. Uji Validitas}

Untuk mengetahui validitas tes hasil belajar diguankan rumus pearson product moment dengan kriteria pengujian dilakukan jika korelasi besarnya 0,361 ke atas maka butir instrumen valid.

Tabel 4.

Hasil Uji Validitas Tes Hasil Belajar

\begin{tabular}{cccc}
\hline No. & & $\begin{array}{c}\text { Nilai Pearson } \\
\text { Correlation }(\mathbf{r})\end{array}$ & Keterangan \\
\hline $\mathbf{1}$ & $\begin{array}{c}\text { Pearson } \\
\text { Correlation } \\
\mathbf{2}\end{array}$ & 0,622 & Valid \\
$\mathbf{3}$ & $\begin{array}{c}\text { Pearson } \\
\text { Correlation } \\
\text { Pearson } \\
\text { Correlation } \\
\text { Pearson }\end{array}$ & 0,558 & Valid \\
$\mathbf{4}$ & $\begin{array}{c}\text { Correlation } \\
\text { Pearson }\end{array}$ & 0,719 & Valid \\
$\mathbf{5}$ & $\begin{array}{c}\text { Correlation } \\
\text { Pearson }\end{array}$ & 0,421 & Valid \\
$\mathbf{6}$ & $\begin{array}{c}\text { Correlation } \\
\text { Pearson }\end{array}$ & 0,649 & Valid \\
$\mathbf{7}$ & $\begin{array}{c}\text { Correlation } \\
\text { Pearson }\end{array}$ & 0,643 & Valid \\
$\mathbf{9}$ & $\begin{array}{c}\text { Correlation } \\
\text { Pearson } \\
\text { Correlation } \\
\mathbf{1 0}\end{array}$ & 0,587 & Valid \\
\hline $\begin{array}{c}\text { Pearson } \\
\text { Correlation }\end{array}$ & 0,447 & Valid \\
\hline
\end{tabular}

Sumber : data yang sudah diolah 


\section{b. Uji Reliabilitas}

Untuk menganalisa data hasil uji coba kuisioner keterampilan berkolaborasi dan tes hasil belajar peneliti menggunakan bantuan SPSS 17. Adapun hasil uji reliabilitas dapat dilihat pada tabel berikut ini.

Tabel 5.

Hasil Uji Reliabilitas Tes Hasil Belajar

\begin{tabular}{rr}
\hline \multicolumn{2}{c}{ Reliability Statistics } \\
Cronbach's Alpha & N of Items \\
.773 & 10 \\
\hline
\end{tabular}

\section{Kuisioner Keterampilan Kolaborasi} a. Uji Validitas

Tabel 6.

Hasil Uji Validitas Angket Keterampilan Kolaborasi

\begin{tabular}{cccc}
\hline No. & Nilai Pearson & Keterangan \\
\hline $\mathbf{1}$ & $\begin{array}{c}\text { Pearrelation }(\mathbf{r}) \\
\text { Correlation } \\
\text { Pearson }\end{array}$ & 0,396 & Valid \\
$\mathbf{2}$ & $\begin{array}{c}\text { Correlation } \\
\text { Pearson }\end{array}$ & 0,652 & Valid \\
$\mathbf{3}$ & $\begin{array}{c}\text { Correlation } \\
\text { Pearson }\end{array}$ & 0,620 & Valid \\
$\mathbf{4}$ & $\begin{array}{c}\text { Correlation } \\
\text { Pearson }\end{array}$ & 0,583 & Valid \\
$\mathbf{5}$ & $\begin{array}{c}\text { Correlation } \\
\text { Pearson }\end{array}$ & 0,612 & Valid \\
$\mathbf{6}$ & $\begin{array}{c}\text { Correlation } \\
\text { Pearson }\end{array}$ & 0,721 & Valid \\
$\mathbf{7}$ & $\begin{array}{c}\text { Correlation } \\
\text { Pearson }\end{array}$ & 0,648 & Valid \\
$\mathbf{8}$ & $\begin{array}{c}\text { Correlation } \\
\text { Pearson }\end{array}$ & 0,555 & Valid \\
$\mathbf{1 0}$ & $\begin{array}{c}\text { Correlation } \\
\text { Pearson } \\
\text { Correlation }\end{array}$ & 0,776 & Valid \\
\hline
\end{tabular}

Sumber : data yang sudah diolah

\section{b. Uji Reliabilitas}

Untuk menganalisis data hasil uji coba item pertanyaan pada variabel keterampilan kolaborasi peneliti menggunakan bantuan SPSS 17. Pengujian reliabilitas instrument ini dilakukan bersamaan dengan pengujian validitas instrumen, karena validitas dan reliabilitas dapat dilaksanakan dalam sekali kegiatan. Adapun analisa uji coba reliabilitas dapat dilihat pada tabel sebagai berikut:

\section{Tabel 7.}

Hasil Uji Reliabilitas Keterampilan Berkolaborasi

\begin{tabular}{cc}
\hline \multicolumn{2}{c}{ Reliability Statistics } \\
Cronbach's Alpha & N of Items \\
.800 & 10 \\
\hline
\end{tabular}

\section{Deskripsi Hasil Penelitian}

Rata-rata kemampuan guru dalam melaksanakan pembelajaran dengan menggunakan model pembelajaran berbasis proyek mencapai rata-rata 11,115 maka kemampuan guru dalam mengelola pembelajaran dapat dikatakan baik. Hasil dari pengamatan pengelolaan pembelajaran dikatakan sebagai data pendukung dalam penelitian. Keterampilan berkolaborasi yang diamati adalah keterampilan yang dilakukan selama proses pembelajaran dengan model PjBL dan pembelajaran konvensional (langsung). Keterampilan yang tampak dalam pembelajaran mencakup : (1) kerja sama, (2) kebebasan berpendapat, (3) mengambil keputusan, (4) pemecahan masalah. Sedangkan pada siswa kontrol siswa diberi pembelajaran konvensional (langsung) dan penugasan secara mandiri.

Tabel 8.

Hasil Keterampilan Kolaborasi dengan Model PjBL

\begin{tabular}{|c|c|c|}
\hline No. & Nama Siswa & Skor \\
\hline 1 & $\overline{\mathrm{ABFG}}$ & 34 \\
\hline 2 & MGR & 35 \\
\hline 3 & AOP & 35 \\
\hline 4 & ASAP & 37 \\
\hline 5 & ALA & 35 \\
\hline 6 & AY & 30 \\
\hline 7 & DRS & 28 \\
\hline 8 & DFH & 39 \\
\hline 9 & DPC & 35 \\
\hline 10 & EESP & 40 \\
\hline 11 & FAPN & 40 \\
\hline 12 & GAS & 40 \\
\hline 13 & GT & 33 \\
\hline 14 & HSR & 40 \\
\hline 15 & IRNR & 37 \\
\hline 16 & JOL & 37 \\
\hline 17 & LDAP & 29 \\
\hline 18 & MRDS & 35 \\
\hline 19 & MLI & 35 \\
\hline 20 & MAOA & 29 \\
\hline 21 & MSA & 35 \\
\hline 22 & NFPY & 40 \\
\hline 23 & PPPS & 37 \\
\hline 24 & RSB & 40 \\
\hline 25 & RAA & 40 \\
\hline 26 & RSA & 40 \\
\hline 27 & RGR & 38 \\
\hline 28 & RAN & 32 \\
\hline 29 & RFHN & 36 \\
\hline 30 & RA & 38 \\
\hline & Rata-Rata & 35,9 \\
\hline
\end{tabular}

Sumber : data yang sudah diolah 
Tabel 9.

Hasil Belajar Siswa dengan Model Project Based Learning

\begin{tabular}{|c|c|c|c|c|c|}
\hline \multirow[t]{2}{*}{$\begin{array}{l}\text { No } \\
\text { - }\end{array}$} & \multirow[t]{2}{*}{$\begin{array}{l}\text { Nama } \\
\text { Siswa }\end{array}$} & \multicolumn{2}{|c|}{ Skor } & \multicolumn{2}{|c|}{$\begin{array}{l}\text { Ketuntasan } \\
\text { Belajar }\end{array}$} \\
\hline & & Pretest & Posttest & Pretest & $\begin{array}{l}\text { Posttes } \\
\text { t }\end{array}$ \\
\hline 1 & ABFG & 70 & 70 & $\mathrm{~T}$ & $\mathrm{~T}$ \\
\hline 2 & MGR & 30 & 80 & TT & $\mathrm{T}$ \\
\hline 3 & AOP & 30 & 40 & TT & TT \\
\hline 4 & ASAP & 40 & 60 & TT & TT \\
\hline 5 & ALA & 30 & 60 & TT & TT \\
\hline 6 & AY & 80 & 90 & $\mathrm{~T}$ & $\mathrm{~T}$ \\
\hline 7 & DRS & 40 & 40 & TT & $\mathrm{T}$ \\
\hline 8 & DFH & 90 & 80 & $\mathrm{~T}$ & $\mathrm{~T}$ \\
\hline 9 & DPC & 70 & 90 & $\mathrm{~T}$ & $\mathrm{~T}$ \\
\hline 10 & EESP & 80 & 80 & $\mathrm{~T}$ & $\mathrm{~T}$ \\
\hline 11 & FAPN & 90 & 90 & $\mathrm{~T}$ & $\mathrm{~T}$ \\
\hline 12 & GAS & 90 & 100 & $\mathrm{~T}$ & $\mathrm{~T}$ \\
\hline 13 & GT & 30 & 50 & TT & TT \\
\hline 14 & HSR. & 80 & 100 & $\mathrm{~T}$ & $\mathrm{~T}$ \\
\hline 15 & INRN & 70 & 90 & $\mathrm{~T}$ & $\mathrm{~T}$ \\
\hline 16 & $\mathrm{JOL}$ & 70 & 70 & $\mathrm{~T}$ & $\mathrm{~T}$ \\
\hline 17 & LDA & 80 & 100 & $\mathrm{~T}$ & $\mathrm{~T}$ \\
\hline 18 & MRDI & 90 & 100 & $\mathrm{~T}$ & $\mathrm{~T}$ \\
\hline 19 & MLI & 80 & 90 & $\mathrm{~T}$ & $\mathrm{~T}$ \\
\hline 20 & MAO & 50 & 100 & TT & $\mathrm{T}$ \\
\hline 21 & MSA & 50 & 70 & TT & $\mathrm{T}$ \\
\hline 22 & NFPN & 50 & 80 & TT & $\mathrm{T}$ \\
\hline 23 & PPP. & 50 & 100 & TT & $\mathrm{T}$ \\
\hline 24 & RSB & 80 & 100 & $\mathrm{~T}$ & $\mathrm{~T}$ \\
\hline 25 & RAA & 60 & 100 & TT & $\mathrm{T}$ \\
\hline 26 & RSA & 30 & 50 & TT & TT \\
\hline 27 & RGR & 30 & 30 & TT & $\mathrm{T}$ \\
\hline 28 & RAN & 40 & 100 & TT & $\mathrm{T}$ \\
\hline 29 & RFHN & 50 & 70 & TT & $\mathrm{T}$ \\
\hline 30 & RA & 30 & 70 & TT & $\mathrm{T}$ \\
\hline \multicolumn{2}{|c|}{ RATA-RATA } & 58,67 & 78,3 & & \\
\hline
\end{tabular}

\section{Analisa Hasil Penelitian}

\section{Uji normalitas}

Uji normalitas data hasil belajar subtema hebatnya cita-citaku dengan menggunakan bantuan computer program SPSS 17 dengan teknik One Sample Kolmogorov-Smirnov pada taraf signifikansi 0,05. Adapun hasil uji normalitas adalah sebagai berikut.

Tabel 10.

Hasil Uji Normalitas

\begin{tabular}{ccc}
\hline Variabel & Kelas & $\begin{array}{c}\text { Kolmogorov- } \\
\text { Smirnov }\end{array}$ \\
\hline $\begin{array}{c}\text { Hasil Belajar } \\
\text { (pretest) }\end{array}$ & Kontrol & $\mathbf{1 . 1 0 3}$ \\
$\begin{array}{c}\text { Hasil Belajar } \\
\text { (posttest) } \\
\text { Hasil Belajar } \\
\text { (pretest) }\end{array}$ & Eksperimen & $\mathbf{1 , 1 5 5}$ \\
$\begin{array}{c}\text { Hasil Belajar } \\
\text { (posttest) }\end{array}$ & $\mathbf{0 , 9 0 1}$ \\
$\begin{array}{c}\text { Keterampilan } \\
\text { Berkolaborasi }\end{array}$ & $\begin{array}{c}\text { Kontrol } \\
\text { Eksperimen }\end{array}$ & $\mathbf{1 , 0 8 6}$ \\
\hline & Sumber : data yang sudah diolah
\end{tabular}

\section{Uji Homogenitas}

Untuk menguji perbedaan hasil belajar dan keterampilan kolaborasi siswa pada kelas eksperimen dan kelas kontrol, digunakan uji Levene's Test of Equality of Error Variances dengan program komputer spss 17.00 .

Tabel 11.

Tes Homogenitas

\begin{tabular}{rrrr}
\hline Levene Statistic & df1 & df2 & \multicolumn{1}{l}{ Sig. } \\
3.524 & 1 & 58 & .066 \\
\hline
\end{tabular}

\section{Pengujian Hipotesa}

Tabel 12.

Tests of Between-Subjects Effects

\begin{tabular}{|c|c|c|c|c|c|}
\hline \multicolumn{6}{|c|}{ Dependent Variable:HB } \\
\hline Source & $\begin{array}{l}\text { Type III Sum of } \\
\text { Squares }\end{array}$ & $\mathrm{df}$ & $\begin{array}{l}\text { Mean } \\
\text { Square }\end{array}$ & $\mathrm{F}$ & Sig. \\
\hline $\begin{array}{l}\text { Corrected } \\
\text { Model }\end{array}$ & $20866.944^{\mathrm{a}}$ & 5 & $\begin{array}{r}4173.38 \\
9\end{array}$ & 20.504 & .000 \\
\hline Intercept & 236220.276 & 1 & $\begin{array}{r}236220 . \\
276\end{array}$ & $\begin{array}{r}1160.53 \\
5\end{array}$ & .000 \\
\hline Model & 2601.948 & 1 & $\begin{array}{r}2601.94 \\
8\end{array}$ & 12.783 & .001 \\
\hline Kolaborasi & 7768.527 & 2 & $\begin{array}{r}3884.26 \\
4\end{array}$ & 19.083 & .000 \\
\hline $\begin{array}{l}\text { model } * \\
\text { kolaborasi }\end{array}$ & 2954.863 & 2 & $\begin{array}{r}1477.43 \\
1\end{array}$ & 7.259 & .002 \\
\hline Error & 10991.389 & 54 & 203.544 & & \\
\hline Total & 291900.000 & 60 & & & \\
\hline $\begin{array}{l}\text { Corrected } \\
\text { Total }\end{array}$ & 31858.333 & 59 & & & \\
\hline
\end{tabular}

Berdasarkan tabel di atas,maka dapat dideskripsikan hasil pengujian hipotesa sebagai berikut :

1. Hipotesa 1

$\mathbf{H}_{\mathbf{0}}$ : Tidak ada pengaruh model Project Based Learning terhadap hasil belajar siswa kelas IV sekolah dasar pada tema cita-citaku.

$\mathbf{H}_{\mathbf{a}}$ : Ada pengaruh model Project Based Learning terhadap hasil belajar siswa kelas IV sekolah dasar pada tema cita-citaku.

Dari hasil uji menggunakan teknik anava dengan $\mathrm{df}$ $=1$ dan taraf signifikansi $\alpha=0,05$, diperoleh nilai $\mathrm{F}=$ 12.783 Dan angka sig. $=0,001$ sangat jauh di bawah 0,05 . Dengan demikian hasil pengujian terhadap hipotesa ke-1 dapat disimpulkan bahwa $\mathbf{H}_{\mathbf{0}}$ ditolak dan $\mathbf{H}_{\mathbf{a}}$ diterima. Jadi dalam penelitian ini dapat dikatakn ada pengaruh penggunaan model Project Based Learning terhadap hasil belajar siswa kelas IV SD pada tema Cita-Citaku. 
2. Hipotesa 2

$\mathbf{H}_{\mathbf{0}}$ : Tidak ada pengaruh keterampilan kolaborasi terhadap hasil belajar siswa kelas IV sekolah dasar pada tema cita-citaku.

$\mathbf{H}_{\mathbf{a}}$ : Ada pengaruh keterampilan kolaborasi terhadap hasil belajar siswa kelas IV sekolah dasar pada tema cita-citaku.

Dari hasil uji menggunakan teknik anava dengan df $=2$ dan taraf signifikansi $\alpha=0,05$, diperoleh nilai $\mathrm{F}=$ 19.083 Dan angka sig. $=0,000$ sangat jauh di bawah 0,05. Dengan demikian hasil pengujian terhadap hipotesa ke-2 dapat disimpulkan bahwa $\mathbf{H}_{\mathbf{0}}$ ditolak dan $\mathbf{H}_{\mathbf{a}}$ diterima. Jadi dalam penelitian ini dapat dikatakan ada pengaruh pelaksanaan keterampilan kolaborasi terhadap hasil belajar siswa kelas IV SD pada tema Cita-Citaku.

3. Hipotesa 3

$\mathbf{H}_{\mathbf{0}}$ : Tidak ada pengaruh model Project Based Learning terhadap hasil belajar siswa kelas IV sekolah dasar pada tema cita-citaku.

$\mathbf{H}_{\mathbf{a}}$ : Ada pengaruh model Project Based Learning terhadap hasil belajar siswa kelas IV sekolah dasar pada tema cita-citaku.

Hasil uji menggunakan teknik anava dengan $\mathrm{df}=2$ dan taraf signifikansi $\alpha=0,05$, diperoleh nilai $F=7.259$ Dan angka sig. $=0,002$ sangat jauh di bawah 0,05. Dengan demikian hasil pengujian terhadap hipotesa ke-3 dapat disimpulkan bahwa $\mathbf{H}_{0}$ ditolak dan $\mathbf{H}_{\mathbf{a}}$ diterima. Sehingga dalam penelitian ini dapat dikatakan ada pengaruh secara bersama-sama (interaksi) penggunaan model Project Based Learning dan keterampilan kolaborasi terhadap hasil belajar siswa kelas IV SD pada tema Cita-Citaku.

Menurut pendapat Budiningsih (2012:41) bahwa proses belajar akan berjalan dengan baik jika guru memberikan kesempatan kepada siswa untuk menemukan suatu konsep dan pemahaman melalui contoh-contoh yang dijumpai dalam kehidupannya. Dalam penelitian ini siswa menemukan konsep-konsep materi yang ada pada bahan ajar komik dengan alur cerita yang bisa mereka jumpai dalam kehidupan sebenarnya. Sedangkan menurut teori Piaget (dalam Budiningsih, 2012:35) bahwa struktur kognitif yang sudah dimiliki seseorang harus disesuaikan dengan informasi yang diterima. Di dalam kelas, anakanak diberi peluang untuk saling berbicara dan diskusi dengan teman- temannya.

\section{PENUTUP}

\section{Simpulan}

Berdasarkan hasil penelitian dan analisis yang dilakukan, maka dapat dikemukakan simpulan sebagai berikut :
Bahwa terdapat pengaruh secara signifikan siswa yang mendapat perlakuan dengan model pembelajaran Project Based Learning terhadap hasil belajar pada siswa kelas IV sekolah dasar tema cita-citaku. Dari hasil kajian empirik menunjukkan adanya perbedaan nilai hasil belajar dari siswa yang mendapat perlakuan model pembelajaran Project Based Learning lebih tinggi dari siswa yang tidak mendapat perlakuan.

Adanya pengaruh secara signifikan siswa yang mendapat perlakuan dengan menggunakan keterampilan kolaborasi terhadap hasil belajar pada siswa kelas IV sekolah dasar tema cita-citaku. Dari hasil kajian empirik menunjukkan adanya perbedaan nilai hasil belajar dari siswa yang mendapat perlakuan dengan keterampilan kolaborasi memiliki nilai lebih tinggi dari siswa yang tidak mendapat perlakuan.

Ada pengaruh secara bersama-sama penggunaan model pembelajaran Project Based Learning dan keterampilan kolaborasi terhadap hasil belajar siswa kelas IV sekolah dasar tema cita-citaku. Dari hasil kajian empirik menunjukkan bahwa nilai hasil belajar siswa kelas IV sekolah dasar tema cita-citaku dipengaruhi adanya interaksi antara model pembelajaran Project Based Learning dan keterampilan kolaborasi

Saran

Terkait dengan hasil penelitian ini, maka beberapa saran yang perlu peneliti sampaikan adalah :

Guru baiknya memfasilitasi siswa dalam pembelajaran dengan menggunakan model Project Based Learning, sehingga siswa menjadi lebih aktif dalam pembelajaran seperti mengajak siswa keluar kelas untuk melakukan pengamatan, menanyakan suatu hal, mengolah data sampai dengan menyajikan data pada proses pembelajaran. Pada akhirnya keterampilan lain dari siswa itu sendiri pada saat proses pembelajaran berlangsung mampu menjadi hidup dan berkembang lebih baik.

Hasil dari kajian empirik (penelitian) tentang penerapan model pembelajaran Project Based Learning dan keterampilan kolaborasi berpengaruh hasil belajar siswa kela IV sekolah dasar tema cita-citaku masih terbatas pada ranah kognitif saja sehingga perlu diadakan penelitian lanjutan untuk kompetisi yang berbeda dalam perbandingan yang sama agar dapat diketahui pula ranah afektif dan ranah psikomotorik siswa.

Bagi peneliti lain, yang akan meneliti hal yang terkait dengan penelitian ini dapat menggunakan variabelvariabel yang lainnya agar lebih bervariatif. 


\section{DAFTAR PUSTAKA}

Arends, R. (2012). Learning to Teach: Ninth Edition. America, New York: Mcgraw-Hill, Inc

Arikunto, Suharsimi. (1989). Manajemen Penelitian. Jakarta: Departemen Pendidikan dan Kebudayaan P2LPTK

Cawi, I Wayan, Dkk. (2014). Vol.4. Pengaruh Model Pembelajaran Berbasis Proyek Terhadap Hasil Belajar Menggambar Layout Dengan Kovariabel Kecerdasan Spasial Dan Kecerdasan Logis Matematis. Bali: Universitas Pendidikan Ganesha Singaraja

Colt. The George Lucas Educational Foundation (2005). Instructional Module Project Based Learning. http://www.edutopia.org/modules/PBL/whatpbl. php (Diunduh pada tanggal 10 Januari 2016)

Fogarty, R. (1991). The Mindful School How To Integrate The Curricula.USA:IRI/Skylight publishing.

Jagantara,I Made,Dkk. (2014). Vol.4. Pengaruh Model Pembelajaran Berbasis Proyek (Project Based Learning) Terhadap Hasil Belajar Biologi Ditinjau Dari Gaya Belajar Siswa SMA.Bali. Program Pascasarjana Universitas Pendidikan Ganesha.

Khamdi. (2007). Model Pembelajaran Berbasis Proyek. Jakarta: Pustaka Karya.

Mustaji. (2009). Teori dan Model Pembelajaran.Surabaya : Unesa University Press.

Mustaji. (2010). Desain Pembelajaran Dengan Menggunakan Model Pembelajaran Kolaborasi Untuk Meningkatkan Kemampuan Berkolaborasi. http://pasca.tp.ac.id/site/ desainpembelajaran-dengan-menggunakan-modelpembelajaran-kolaborasi-untuk-meningkatkankemampuan-berkolaborasi (diakses pada tanggal 05 Januari 2016).

Nurochman, Sabar. (2007). Pendekatan Project Based Learning Sebagai Upaya Internalisasi Scientific Method Bagi Mahasiswa Calon Guru Fisika. FMIPA Universitas Negeri Yogyakarta.

Pusat Pengembangan Profesi Pendidik Badan Pengembangan Sumber Daya Manusia Pendidikan dan Kebudayaan dan Penjaminan mutu Pendidikan. 2014. Materi Pelatihan Guru Implementasi Kurikulum 2013 SD Kelas II. Jakarta: Kementrian Pendidikan dan Kebudayaan.

Rachmawati, Dini. (2011). Pengaruh Model Pembelajaran Berbasis Proyek Terhadap Hasil Belajar Fisika Siswa.FITK Universitas Islam Negeri Syarif Hidayatullah. Jakarta.
Riduwan. (2010). Belajar Mudah Penelitian untuk Guru, Karyawan dan Peneliti Pemula. Bandung: Alfabeta.

Sekiyani, Dwi. (2012).Implementasi Metode Kolaborasi Dalam Meningkatkan Keterampilan Menulis Narasi Siswa Kelas $V$ SD.FIP Universitas Sebelas Maret.

Subagia, I Wayan dkk. Vol.4. No.1. (2014). Pengaruh Model Pembelajaran Berbasis Proyek Terhadap Hasil Belajar Ipa Ditinjau Dari Self Efficacy Siswa. Bali: Program Pascasarjana Universitas Pendidikan Ganesha.

Sudjana, Nana. (2009). Dasar- Dasar Proses Belajar Mengajar. Bandung: PT Sinar Baru Algensindo

Sugiyono. (2010). Metode penelitian kuantitatif kualitatif dan R\& D. Bandung: Alfabeta

Sujarweni, Wiratna. (2014). SPSS Untuk Penelitian. Yogyakarta: Pustaka Baru Press

Triani, Wina (2015). Pengaruh Model Pembelajaran Project Based Learning Terhadap Hasil Belajar Geografi. FKIP Universitas Lampung.

Trianto. (2007). Model Pembelajaran Terpadu dalam Teori dan Praktek. Jakarta: Prestasi Pustaka

Trianto. (2011). Mendesain Pembelajaran Kontekstual di kelas (Contekstual Teaching Learning). Jakarta: Cerdas Pustaka.

Undang-Undang Nomor 20 Tahun 2003 Tentang Sistem Pendidikan Nasional. Jakarta: Kemendikbud.

Wrigley. (1998). Knowledge in Action: The Promise of Project-Based Learning. http://repository.upi.edu/operator/uploads/s (Diakses pada tanggal 10 Januari 2016). 